\title{
PAPER \\ Plate-Laminated Waveguide Monopulse Slot Array Antenna with Full-Corporate-Feed in the E-Band
}

\author{
Xin $\mathrm{XU}^{\dagger \mathrm{a})}$, Student Member, Jiro HIROKAWA ${ }^{\dagger}$, and Makoto $\mathrm{ANDO}^{\dagger}$, Fellows
}

\begin{abstract}
SUMMARY This paper presents the design and characterization of an E-band $16 \times 16$-slot monopulse array antenna with full-corporate-feed fabricated by the commercially available batch process of diffusion bonding of laminated copper plates. The antenna is multi-layered, and consists of vertically-interconnected radiating elements, a corporate-feed circuit and a comparator. It has four input ports for different excitations. Sum and difference beams in different cut-planes for monopulse operation can be generated. The antenna has a quasi-planar profile, and a total size of 13.31 $\lambda_{0} \times 13.31 \lambda_{0} \times 1.52 \lambda_{0}\left(\lambda_{0}\right.$ is the wavelength at the design frequency of $78.5 \mathrm{GHz}$ ). The antenna demonstrates a wide operation bandwidth of 17.2 (70-87.2) GHz for VSWR <2. At 78.5 GHz: 1) for the sum beam, there is a 32.6-dBi realized gain (83\% antenna efficiency) and a 33.3-dBi directivity (95\% aperture efficiency); 2) for the difference beams in the E-, $\mathrm{H}-, 45^{\circ}$-, and $135^{\circ}$-planes, the null depths are $-53.0,-58.0,-57.8$, and $-65.6 \mathrm{~dB}$, respectively. Across the full operation band where the sum main-beam and difference null are able to consistently point at the boresight, the antenna also demonstrates excellent performance in terms of high gain, high efficiency, high isolation, low cross-polarization, and distinguished monopulse capability.

key words: E-band, waveguide slot antenna, millimeter-wave antenna, monopulse array antenna, comparator, diffusion bonding
\end{abstract}

\section{Introduction}

Monopulse is an established technique capable of processing fast and accurate solutions to determine electronically the direction of arrival of echoes and target locations with precise angle estimates in radar systems [1], [2]. The monopulse principle only assures an improved resolution in the angular direction, while the range resolution essentially depends on the bandwidth of the carrier signal. A narrow beamwidth enables a better angle accuracy in monopulse tracking operations. For an ultra-high range-resolution, much more bandwidth, commonly $20 \%$ larger is required [3], [4]. The demands of this larger bandwidth has traditionally been delivered with lower frequency bands such as the ultra-wideband channel (3.1-10.6 GHz), the Ka-band (22-29 GHz), and others. However, serious issues arise in the usage of these very crowded and heavily-utilized lower frequency bands due to the harmful interference from co-existing in- or adjacentbands, as well as the low data throughput with maximum data rates of only hundreds of Mbps [5]. In recent years, the broadbanded E-band at the $71-76$ and $81-86 \mathrm{GHz}$ bands

Manuscript received July 11, 2016.

Manuscript revised September 23, 2016.

Manuscript publicized October 28, 2016.

$\dagger$ The authors are with the Department of Electrical and Electronic Engineering, Tokyo Institute of Technology, Tokyo, 1528552 Japan.

a)E-mail: xinxu@ antenna.ee.titech.ac.jp DOI: 10.1587/transcom.2016EBP3271 have received increasing attention to address this issue. The E-band can support stable multi-gigabit wireless connectivity over long distances with robust weather resilience and fewer interference concerns with cost-effective/reliable architectures [6].

The choice of an appropriate transmission line is a fundamental and critical issue when determining antenna efficiency. The monopulse array antenna based on traditional transmission lines [7]-[10] (microstrip line and dielectricfilled waveguides) suffer from intrinsic losses which degrade the antenna efficiency. This degradation becomes more notable for high-gain applications in the millimeter-wave band.

The feeding network and comparator are key components in determining the bandwidth of antenna monopulse capability. A corporate-feed network is devoted to wideband operation as long-line effects [7], [9]-[12] can be fully eliminated so that each radiating unit can be fed uniformly regardless of the frequency. In comparison to a single-layer counterpart implemented by a 3-dB coupler associated with a $90^{\circ}$ phase shifter [7]-[10], a comparator implemented by $180^{\circ}$ hybrids [11], [12] can maintain a better amplitude/phase balance in a wider bandwidth. In [8], the corporate-feed architecture is adopted, but the phase/amplitude deviation of the comparator will still limit the bandwidth of antenna monopulse capability.

The waveguide structure has the potential to offer low loss and slimness and is the leading candidate for millimeterwave applications. Use of the multi-layer waveguide architecture is indispensable to realize a $180^{\circ}$ hybrid and the corporate-feed network associated with radiating elements above it, and it also enables compact devices with reduced transmission losses in the interconnection between the comparator and the feeding circuit. However, using traditional machining approaches to fabricate and manufacture these complicated and sophisticated three-dimensional components in the millimeter-wave band is prohibitively expensive and time-consuming. Additionally, the reliable and reproducible assembly of the components into a final massproduced product at a competitive cost is still a challenge as the electrical performance in the millimeter-wave band is highly sensitive to the assembly quality. A bulky profile after assembly also poses considerable disadvantages in integration into a compact front-end sub-system. Very recently, a Ku-band waveguide monopulse array antenna has been demonstrated using a 3-D metal-direct-printing technique [13]. However, the feasibility of using this fabrication method to realize complicated antenna arrays in the 
millimeter- wave band has yet to be adequately demonstrated. This is because the choice of metal material, the surface roughness, and the fabrication accuracy can severely degrade the antenna performance in millimeter-wave band.

Diffusion bonding of laminated thin metal plates is a commercially available fabrication technique which allows dispensing with additional tuning and assembly processes after the bonding. It has advantageous features such as high accuracy (about $\pm 20 \mu \mathrm{m}$ ), reproducibility, reliability, and suitability for mass-production and could provide waveguide fabrication and packaging solutions for millimeter-wave and sub-millimeter-wave applications. The surface roughness and the electrical contact among the plates in fabrication can be very good. For instance, in [15], the measured overall antenna loss of a $16 \times 16$-slot array antenna in the E-band is estimated to be 1-2 times to the simulated one with an assumed conductivity of $5.8 \times 10^{7} \mathrm{~S} / \mathrm{m}$ for copper. In recent years, the authors have been actively engaged in the demonstration of highly-efficient plate-laminated waveguide slot array antennas with corporate-feed using diffusion bonding technology. Various functions with respect to the operating frequency [14], polarization [15], the gain [16], the bandwidth [17] and other features have been explored based on the basic architecture [18]. All of these antennas only work with fixed beams since the corporate-feed circuit is only used for the equal signal-distribution and no other function.

In this paper, the authors detail their first study on the beam-forming of a plate-laminated waveguide slot array antenna with full-corporate-feed by adding monopulse processing functionality to the feeding circuit to effectively control the phase distribution among the radiating units. A consequent $16 \times 16$-slot array antenna for the E-band monopulse applications is developed. The antenna is composed of radiating elements, a corporate-feed circuit, and a comparator, which are vertically interconnected. The radiating elements are uniformly fed through the full-corporate-feed circuit. Self-symmetrical magic-T's and their folded counterparts are adopted for implementing a comparator with high isolation, high robustness against fabrication tolerances, as well as frequency-independent amplitude/phase balance. Reflection of each of the sub-components is sufficiently suppressed over a wide bandwidth with several traditional components [14]-[18] (H-junction, E-bend, and a double-layered interconnecting circuit) remarkably improved.

The design procedure will be described in detail with guidelines provided. Design challenges beyond our previous studies that forced here in terms of fabrication stability, compactness, optimal performance, optimal interconnection and so on have been addressed and resolved. A prototype is fabricated, and tested to validate the design approach by comparing with the theoretical predictions. This work represents the first demonstration of an array antenna attractive for millimeter-wave band ultra-high range-resolution monopulse tracking radar applications achieved by a massproducible waveguide fabrication method.

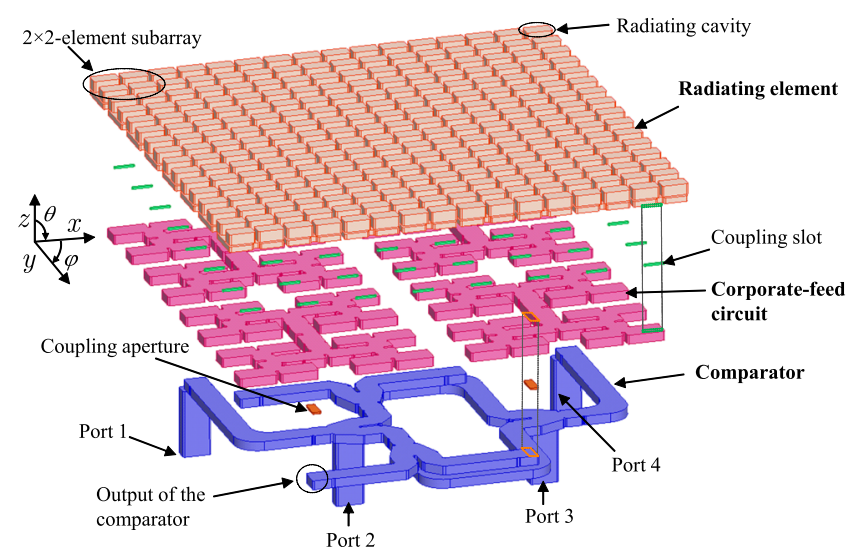

(a)

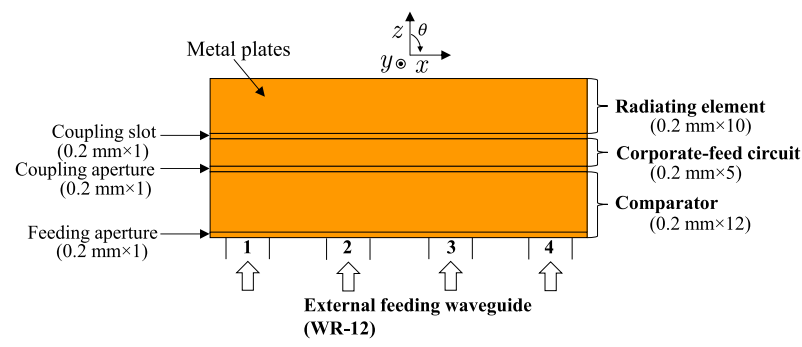

(b)

Fig. 1 Proposed $16 \times 16$-element monopulse array antenna. (a) Architecture. (b) Stacking arrangement.

\section{Antenna Configuration and Operation Mechanism}

Figure 1 shows the architecture and the stacking arrangement of the proposed monopulse array antenna. The thickness is $5.8 \mathrm{~mm}$, a laminate of twenty-nine etched metal plates of identical thickness, each $0.2 \mathrm{~mm}$ thick. The radiating element, the corporate-feed circuit, and the comparator are formed by 10,5 , and 12 plates, respectively. The dimension of the waveguide employed in the antenna is $2.4 \mathrm{~mm} \times$ $1.0 \mathrm{~mm}$. The design frequency is $78.5 \mathrm{GHz}$ and the design frequency band is from 67 to $90 \mathrm{GHz}$.

The antenna radiates a wave through the radiating cavities located on the top layer. The E-plane of the antenna coincides with the $y z$-plane $\left(90^{\circ}\right.$-plane) while the H-plane coincides with the $x z$-plane $\left(0^{\circ}\right.$-plane). The radiating cavities are spaced at fixed distances in the $x$ - and $y$-directions. The corporate-feed circuit consists of four identical parts with cascaded H-plane T-, and H-junctions. The sixteen coupling slots are arranged between the radiating elements and the corporate-feed circuit, and occur at the end of $\mathrm{H}$-junctions. The $2 \times 2$-element subarrays of the radiating elements are uniformly fed by each end of an $\mathrm{H}$-junction through the coupling slot. The comparator with four input ports (Ports 1-4) and four output ports is implemented by four magic-T's. The comparator and the corporate-feed circuit are interconnected through the coupling apertures which are located at the end of the output waveguide of the comparator. The coupling 


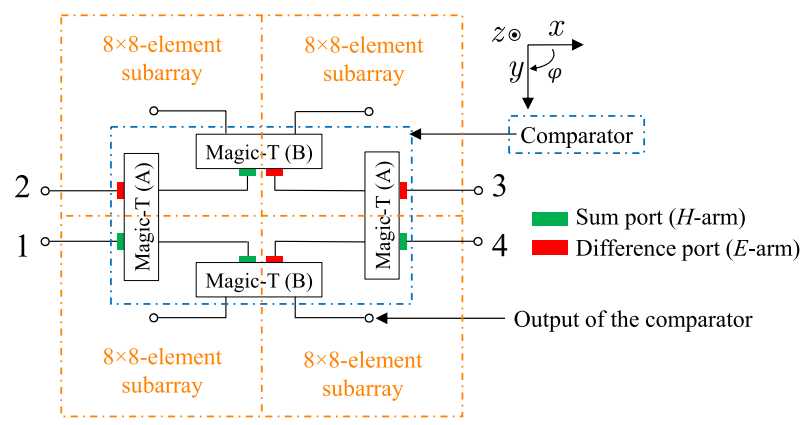

(a)

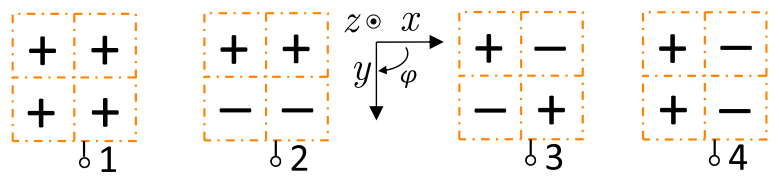

(b)

Fig. 2 Proposed $16 \times 16$-element monopulse array antenna. (a) Block diagram. (b) Operating mechanism.

aperture is incorporated by a double-layered interconnecting circuit. The antenna is fed by standard WR-12 waveguides $(3.10 \mathrm{~mm} \times 1.55 \mathrm{~mm})$ from the back through the feeding apertures etched in the bottom plate.

Figure 2 shows a block diagram and the operating mechanism of the antenna. The radiating elements can be viewed as four identical quadrants. Each quadrant represents one $8 \times 8$-element subarray and is effected by one output port of the comparator. The radiating cavities within one quadrant all have the same phase distribution, however the overall phase distribution among the four quadrants can be controlled by the phase transformation over the difference/sum ports of these magic-T's. When Port 1 is excited, the sum beam is generated; when Port 2 or 4 is excited, the difference beam is generated in the E-plane or H-plane, respectively; when Port 3 is excited, the difference beams in the crossplanes $\left(45^{\circ}\right.$ - and $135^{\circ}$-planes) are generated.

The commercial software HFSS 14 and 16 were used to perform the simulations conducted here, and copper with a conductivity of $5.8 \times 10^{7} \mathrm{~S} / \mathrm{m}$ is used throughout the simulations.

\section{Design of the Building Blocks}

\subsection{Radiating Element}

We developed a wideband $2 \times 2$-element subarray in the Eband [15], $45^{\circ}$ polarized to maintain a low sidelobe level at its co-polarization plane, which however cannot coincide with the plane for the monopulse operation considered here. Further, the rotation of the radiating cavity will unavoidably degrade the cross-polarization level.

Based on the above considerations, we propose a $2 \times 2$ element with $0^{\circ}$ polarization suitable for the monopulse operation considered here which is able to maintain a satisfactory

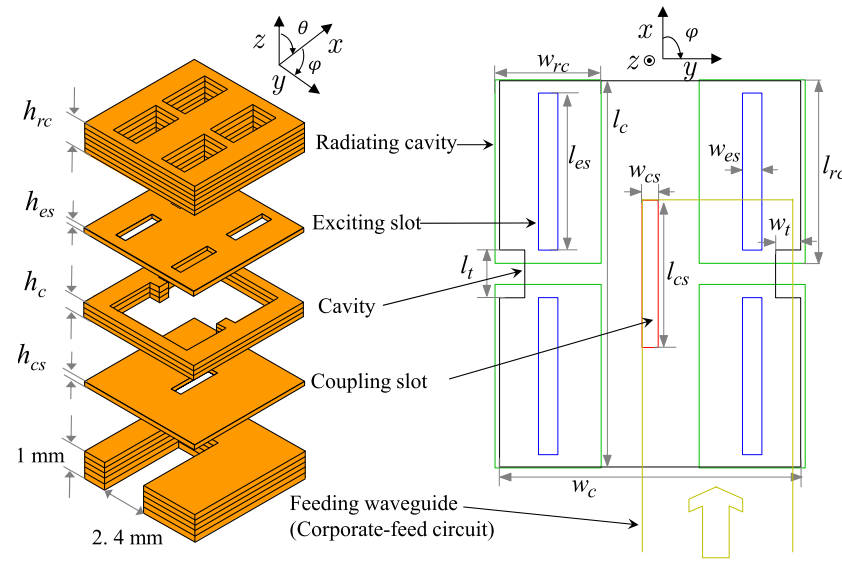

Fig. 3 Architecture of the proposed $2 \times 2$-element subarrays.

Table 1 Design parameters of a $2 \times 2$-element subarray.

\begin{tabular}{ccc}
\hline Design parameters & & Value (mm) \\
\hline Distance between adjacent radiating cavities & $\backslash$ & 3.18 \\
Thickness of the radiating cavity & $h_{r c}$ & 1.20 \\
Thickness of the exciting slot & $h_{e s}$ & 0.20 \\
Thickness of the cavity & $h_{c}$ & 0.60 \\
Thickness of the coupling slot & $h_{c s}$ & 0.20 \\
Width, length of the radiating cavity & $w_{r c}, l_{r c}$ & $1.65,2.85$ \\
Width, length of the exciting slot & $w_{e s}, l_{e s}$ & $0.30,2.44$ \\
Width, length of the cavity & $w_{c}, l_{c}$ & $4.69,6.00$ \\
Width, length of the cavity wall & $w_{t}, l_{t}$ & $0.39,0.74$ \\
Width, length of the coupling slot & $w_{c s}, l_{c s}$ & $0.25,2.29$ \\
\hline
\end{tabular}

radiation performance, as shown in Fig. 3. It is composed of one coupling slot, one cavity, four narrow exciting slots, and four $0^{\circ}$ polarized radiating cavities, occupying four etching patterns. The narrow exciting slot between the radiating cavity and the cavity is aimed at suppressing the grating lobe generated by the wide radiating cavity [17].

The distance between two adjacent radiating cavities is set to $3.18 \mathrm{~mm}\left(0.83 \lambda_{0}\right.$ at $\left.78.5 \mathrm{GHz}\right)$. Two pairs of walls with periodic boundary conditions are imposed above the radiating cavities to take the mutual coupling effect from adjacent subarrays into account. In addition, the array-setup functionality is used to predict the radiation characteristics of the array antenna. The design parameters have been fully tuned to broaden the operation bandwidth [17], [18]. The final design parameters are listed in Table 1.

Figure 4 shows the simulated reflection and cross polarization of the proposed $2 \times 2$-element subarray. At $67-90 \mathrm{GHz}$, a wide bandwidth for impedance matching is achieved, $21.8 \%$ for VSWR $<1.5$ with the poorest local value of $-19.6 \mathrm{~dB}$. The cross polarization at the boresight within the design frequency band is below $-64 \mathrm{~dB}$, showing a promising enhancement compared to that in [15], where additional narrow slot pairs were adopted.

\subsection{Corporate-Feed Circuit}

Figure 5 shows a half bisection of a quarter of the corporatefeed circuit. It occupies one etching pattern, and is obtained 


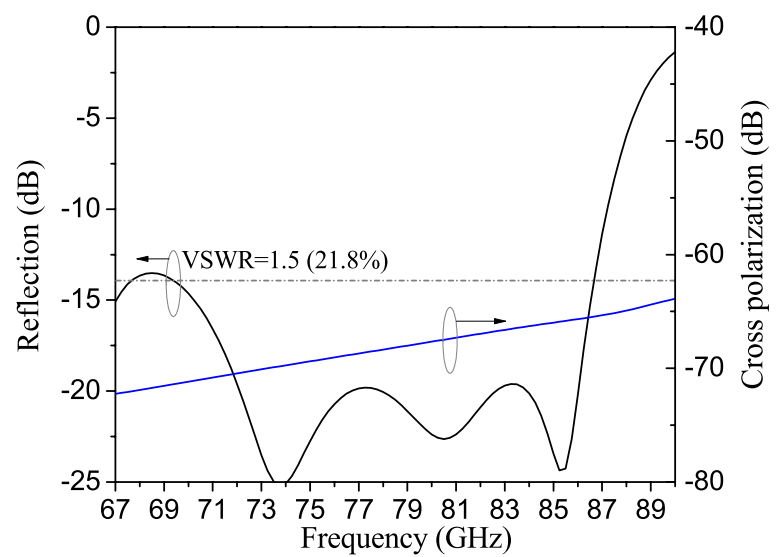

Fig. 4 Simulated reflection and cross polarization of the proposed $2 \times 2$ element subarray.

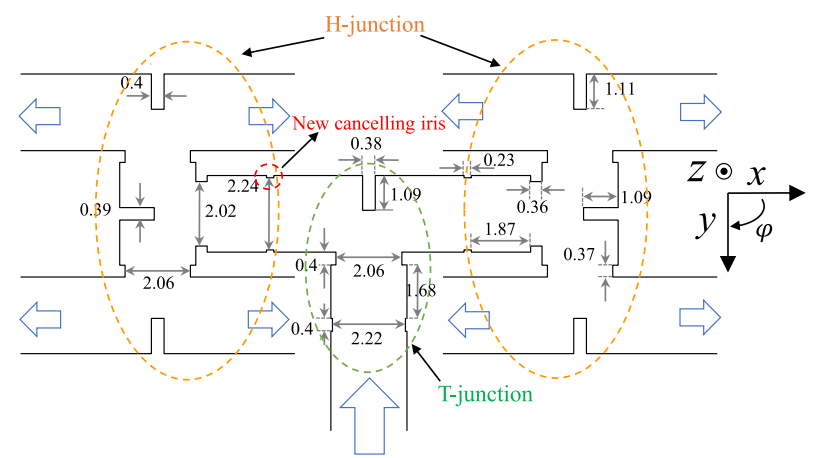

Fig.5 Half bisection of a quarter of the corporate-feed circuit. Unit: millimeters.

by scaling down the $\mathrm{H}-$ plane, $\mathrm{T}-$, and $\mathrm{H}$-junctions presented in [18]. However, improvements of the design have been made on the $\mathrm{H}$-junction by introducing a cancelling iris, which is approximately a quarter of the guided wavelength away from the window, as indicated in Fig. 5. In this situation, the reflection from the window can be further reduced by cancelling with the reflection from the iris due to the $180^{\circ}$ phase difference.

Figure 6 shows the reflection characteristics of the junctions and the corporate-feed circuit. The bandwidth of the $\mathrm{T}$-junction for reflection $<-20 \mathrm{~dB}$ is $27.2 \%$. The bandwidth of the $\mathrm{H}$-junction for reflection $<-20 \mathrm{~dB}$ has been improved from $20.5 \%$ to $23.1 \%$ with the cancelling iris, and the poorest local value from -22.7 to $-30.6 \mathrm{~dB}$. Consequently, the bandwidth of the corporate-feed circuit for reflection $<-20 \mathrm{~dB}$ has been improved from $18.5 \%$ to $22.1 \%$, with the poorest local value from -21.1 to $-25.4 \mathrm{~dB}$.

\subsection{Comparator}

The magic-T is a critical component of the comparator, therefore the stability and practicality of the magic-T from the standpoint of fabrication is the starting point for the design. The magic-T's presented in [12], and [19]-[22] have an important feature in common in that they all adopt a scheme

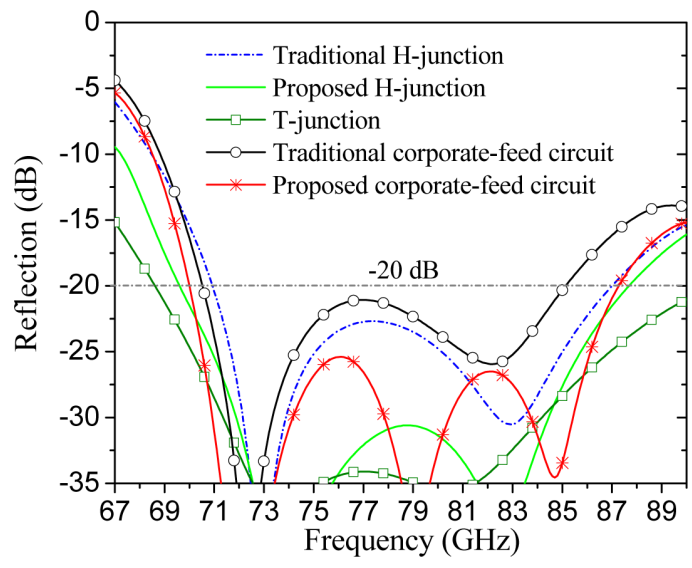

Fig. 6 Simulated reflection characteristics of the junctions and the corporate-feed circuit.

with T-shaped junctions, and the matching elements formed by wedge, post, cone, iris and other features are centered inside the junction. However, in the fabrication process using diffusion bonding of laminated thin metal plates, the top surface of these matching elements must be free from mechanical pressure due to the E-plane waveguide branch above, and the result may be imperfect bonding [23] due to the low (absent) pressure, resulting in deformations and air gaps between the plates forming the matching element. Here, the Y-shaped junction is considered to ensure fabrication stability.

Figure 7 shows the geometry and the stacking arrangement of the proposed comparator, which is a double-layered structure incorporating four etching patterns. The thickness of each layer is $1 \mathrm{~mm}$, the coupling/feed apertures and coupling slots are positioned in the middle and bottom plates. The comparator is implemented by four magic-T's, two of which are denoted as (A) and two as (B). The difference and sum ports of the (A) magic-T's serve as the input ports of the comparator; while the ports of (B) magic-T's for powerdividing serve as the output ports of the comparator and are coupled with the corporate-feed circuit. To connect the external WR-12 waveguide, the H-arms of the (A) magic-T's are extended by E-bends. Several L-shaped waveguides are employed for the transition. To accommodate the waveguide flanges in the measurements, the distance between adjacent feeding apertures is selected to be larger than $20 \mathrm{~mm}$.

Figure 8 shows the geometry and simulated reflection characteristic of the E-bend. With principles similar to those presented in the previous subsection, the E-bend with the newly introduced cancelling irises show a greatly improved bandwidth for reflection $<-25 \mathrm{~dB}$, i.e. $19.4 \%(70.8-86 \mathrm{GHz})$ compared the traditional E-bend [18].

Figure 9 shows the geometry and the frequency characteristic of the magic-T's. A (A) magic-T consists of an $\mathrm{H}$-plane junction and an E-plane junction, and the shared junction is formed by a Y-shaped bifurcation. The shape of the impedance-transformer at the junction is crucial for matching the E- and $\mathrm{H}$-arms simultaneously, while many irises are also added for further tuning the impedance match- 


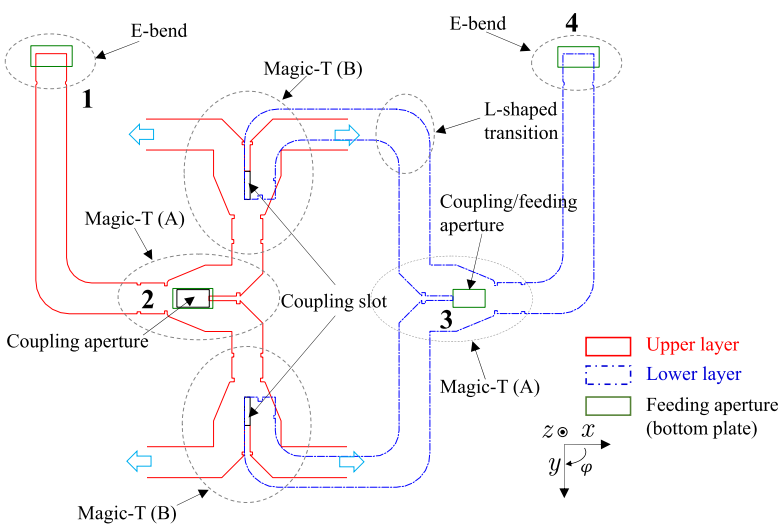

(a)

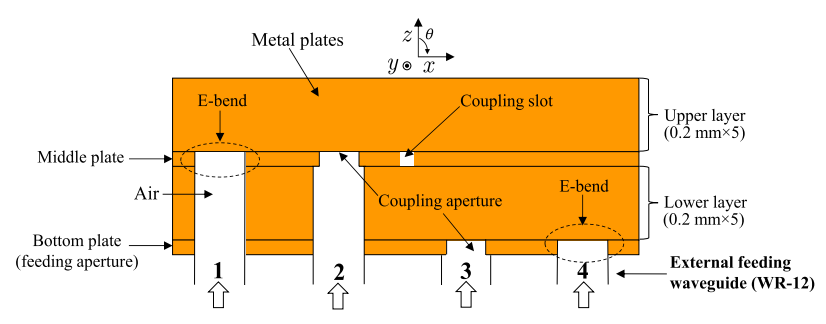

(b)

Fig. 7 Proposed comparator. (a) Geometry. (b) Stacking arrangement.

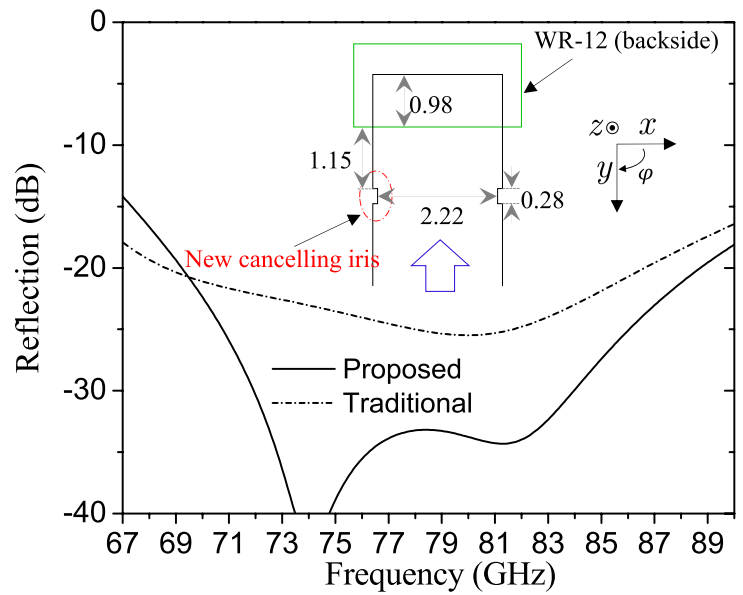

Fig. 8 Simulated reflection characteristic of the proposed E-bend, with inserted geometry. Unit: millimeters.

ing. The E- and H-arms of the (A) magic-T are mutually perpendicular, and have centerlines in one symmetry plane of the junction. The coupling aperture is arranged between the E-arm and the junction. Such self-symmetry guarantees a perfect isolation between the sum and difference ports and the desired phase difference between the two output ports. The power-dividing arms after the junction are rotated by $90^{\circ}$ to facilitate the interconnection between the magic-T's.

To achieve structural compactness and simplification, the (B) magic-T used in the comparator is obtained by folding the E-arm of the above (A) magic-T toward the lower layer, with a transverse coupling slot etched in the middle

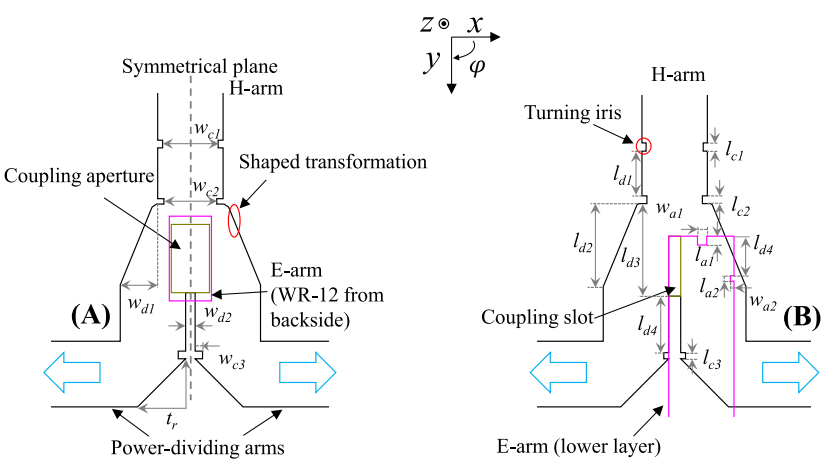

(a)

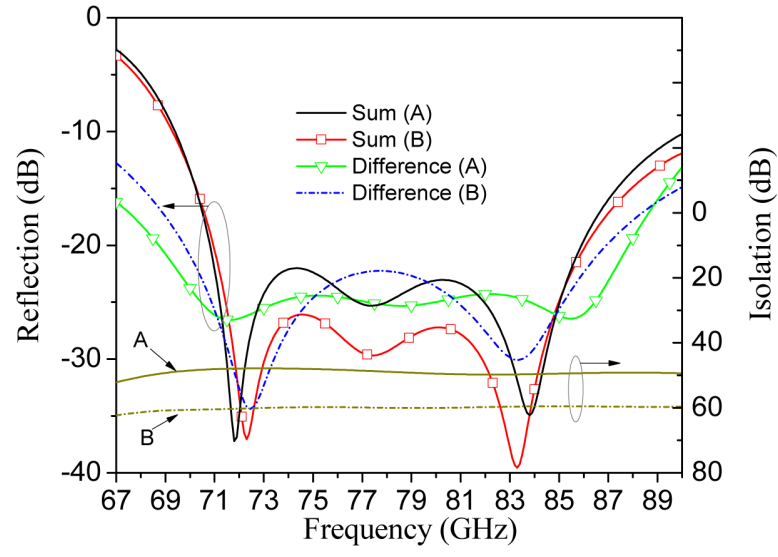

(b)

Fig. 9 Proposed magic-T. (a) Geometry. (b) Simulated reflection and isolation characteristics.

plate. In this way, the E-arms of the (B) magic-T's and the power-dividing arms of the (A) magic-T can be placed in the same layer, and interconnected through L-shaped waveguides without a vertical transition, avoiding an increase in thickness and number of etched patterns.

No rigorous theoretical treatments represented with an equivalent circuit as a starting point would be directly applicable to the design of such waveguide hybrid junctions. But the design problem can be reduced to that of maintaining symmetry and simultaneously suppressing the reflection from the $\mathrm{E}$ - and $\mathrm{H}$-arms by electromagnetic-based optimization [19]-[22]. All the design parameters indicated in Fig. 9(a) have been fully optimized to broaden the bandwidth and the final values are listed in Table 2. As shown in Fig. 9(b), the bandwidth of the sum ports for reflection $<-20 \mathrm{~dB}$ is $19.1 \%(70.9-85.9 \mathrm{GHz})$; while that of the difference ports is $21.8 \%(69.8-86.9 \mathrm{GHz})$. The isolation of the (A) and (B) magic-T's are better than 45 and $60 \mathrm{~dB}$, respectively.

Figure 10(a) shows the simulated reflection characteristics of the comparator (including the E-bends and the Lshaped transitions). The bandwidth of the input ports for VSWR $<1.5$ is $21.1 \%(70.6-87.2 \mathrm{GHz})$.

Figure 10(b) shows the simulated amplitude/phase error of the comparator. The amplitude error for one of the input ports is defined as the difference between the max- 
Table 2 Design parameters of the magic-T.

\begin{tabular}{|c|c|c|c|c|c|}
\hline \multirow{2}{*}{$\begin{array}{c}\text { Design } \\
\text { parameters }\end{array}$} & \multicolumn{2}{|c|}{ Value (mm) } & \multirow{2}{*}{$\begin{array}{c}\text { Design } \\
\text { parameters }\end{array}$} & \multicolumn{2}{|c|}{ Value (mm) } \\
\hline & (A) & (B) & & (A) & (B) \\
\hline$l_{c l}$ & 0.30 & 0.28 & $w_{c l}$ & 2.10 & 2.04 \\
\hline$l_{c 2}$ & 0.29 & 0.20 & $w_{c 2}$ & 2.04 & 1.94 \\
\hline$l_{c 3}$ & 0.23 & 0.28 & $w_{c 3}$ & 0.18 & 0.27 \\
\hline$l_{d l}$ & 1.64 & 1.86 & $w_{d l}$ & 1.46 & 1.47 \\
\hline$l_{d 2}$ & 3.04 & 2.95 & $w_{d 2}$ & 0.44 & 0.35 \\
\hline$l_{d 3}$ & 3.39 & 3.24 & $t_{r}$ & 1 & 1.76 \\
\hline$l_{d 4}$ & 2.07 & 2.14 & $w_{a l}$ & 1 & 0.34 \\
\hline$w_{a 2}$ & 1 & 0.13 & $l_{a l}$ & 1 & 0.32 \\
\hline$l_{a 2}$ & $\backslash$ & 0.20 & $l_{d 4}$ & 1 & 1.45 \\
\hline $\begin{array}{l}\text { Width/length } \\
\text { of the } \\
\text { coupling slot }\end{array}$ & 1 & $\begin{array}{l}0.44 / \\
2.20\end{array}$ & $\begin{array}{l}\text { Width/length } \\
\text { of the coupling } \\
\text { aperture }\end{array}$ & $\begin{array}{l}1.40 / \\
2.50\end{array}$ & 1 \\
\hline
\end{tabular}

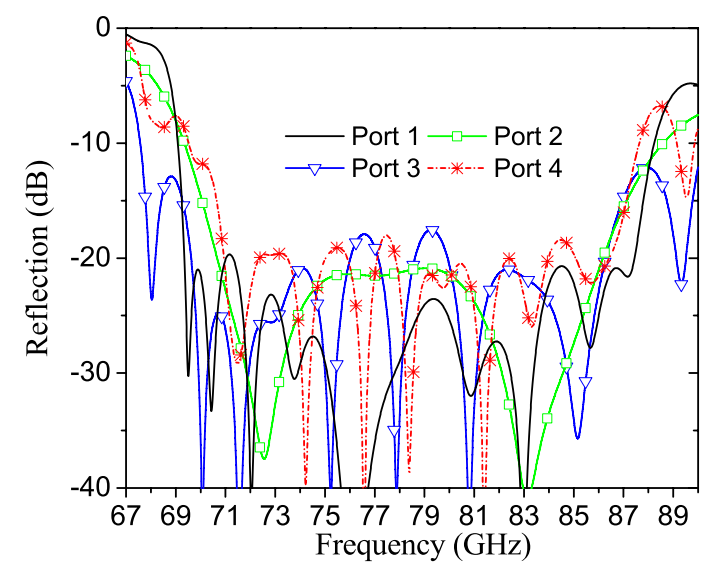

(a)

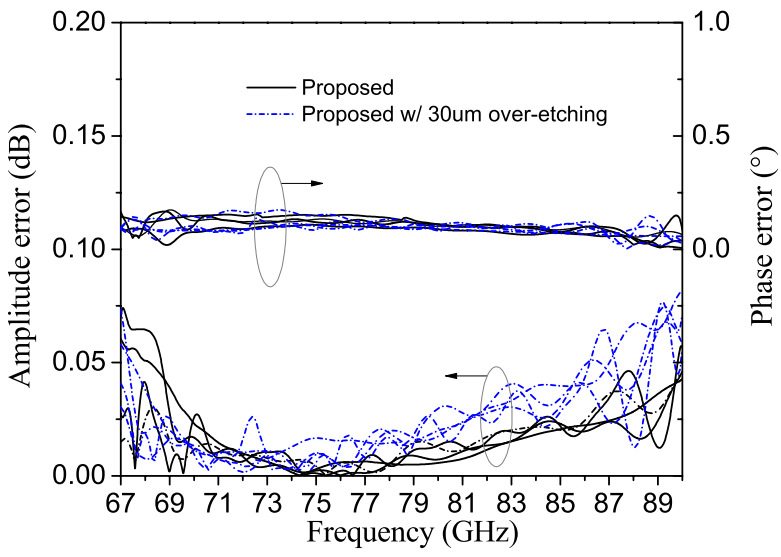

(b)

Fig. 10 Simulated results of the proposed comparator. (a) Reflection characteristic. (b) Amplitude/phase error.

imum and the minimum amplitudes among all the output ports. The phase error for one of the input ports is defined as the difference between the ideal and the average of the phase difference between adjacent output ports. The simulated amplitude and phase errors across $67-90 \mathrm{GHz}$ are small to negligible, less than $0.07 \mathrm{~dB}$ and $0.2^{\circ}$, respectively. From this it may be concluded that a frequency-independent

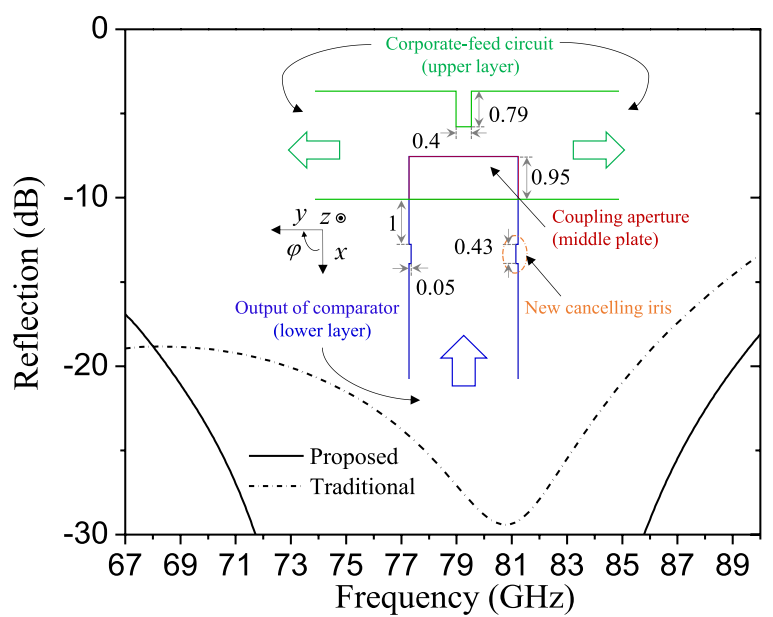

Fig. 11 Simulated reflection characteristic of the proposed double-layer interconnecting circuit, with inserted geometry. Unit: millimeters.

Table 3 Information in the full-model simulation

\begin{tabular}{cccccc}
\hline $\begin{array}{c}\text { Number } \\
\text { of pass }\end{array}$ & $\begin{array}{c}\text { Max } \\
\text { delta S }\end{array}$ & $\begin{array}{c}\text { Mesh } \\
\text { elements }\end{array}$ & $\begin{array}{c}\text { Max } \\
\text { memory } \\
\text { used }\end{array}$ & $\begin{array}{c}\text { Frequency } \\
\text { step }\end{array}$ & $\begin{array}{c}\text { Total } \\
\text { calculation } \\
\text { time }\end{array}$ \\
\hline 14 & 0.0008 & 3187789 & $140 \mathrm{~GB}$ & $\begin{array}{c}0.5 \mathrm{GHz} \\
(47 \text { points })\end{array}$ & 26.5 hours \\
\hline
\end{tabular}

monopulse processing capability of the comparator has been successfully implemented.

In the fabrication process of diffusion bonding of laminated thin metal plates, errors mainly arise due to the etching and laminating processes, and may be considered to be a result of over-etching, something which is practically within the extent of $0-30 \mu \mathrm{m}$. Including the effect of the worst case by imposing $30-\mu \mathrm{m}$ of over-etching on all the design parameters of the comparator, results in the simulated results shown in Fig. 10(b). With this imposed error, amplitude and phase errors are nearly unchanged, suggesting the inherent robustness of the comparator against fabrication errors.

\section{Antenna Implementation and Simulated Results}

For the antenna, the proposed building blocks are integrated to create a $16 \times 16$-slot array antenna, and a problem here is the interconnection between the corporate-feed and the comparator. To avoid overlap between the corporate-feed circuit and the comparator in co-plane interconnection, here we adopt a double-layered interconnecting circuit formed by adding a pair of cancelling irises to the one proposed in [14].

Figure 11 shows the geometry and the simulated result of the adopted double-layer interconnecting circuit. The bandwidth for reflection $<-25 \mathrm{~dB}$ is $21.4 \%$ (70.5$87.3 \mathrm{GHz}$ ), which is a great improvement compared to the traditional circuit [14].

The full model of the $16 \times 16$-element monopulse array antenna has been simulated by using the HFSS ver.14 on a Dell Precision-T7600 Workstation (CPU: dual-core Intel Xeon E5-2687W0, 3.10 GHz). Table 2 summaries the information in simulation. 


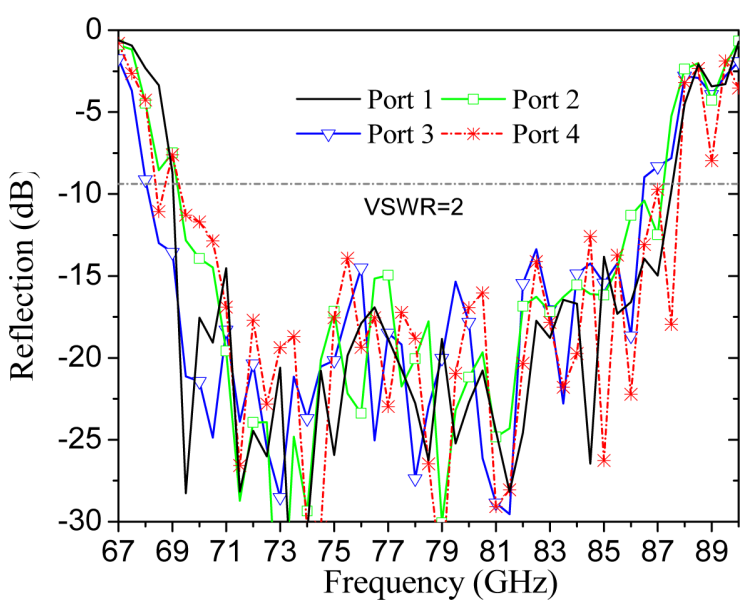

Fig. 12 Simulated reflection characteristic of the proposed antenna.

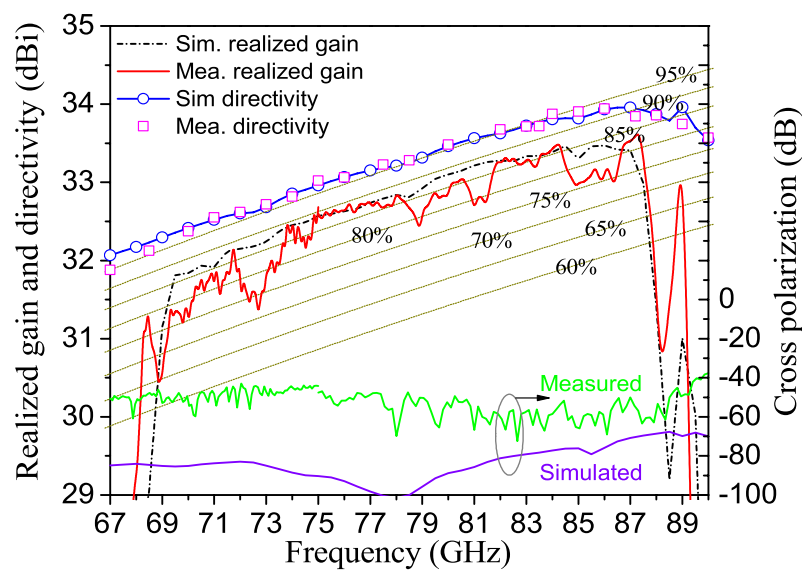

Fig. 13 Realized gain, directivity and cross polarization of the sum pattern at boresight.

Figure 12 shows the simulated reflection characteristic of the antenna. The bandwidth for VSWR $<2$ at the both input ports is $21.8 \%(69.4-86.5 \mathrm{GHz})$.

Figure 13 shows the simulated realized gain, the directivity, and the cross polarization of the sum beam (Port 1) at the boresight. At the design frequency of $78.5 \mathrm{GHz}$, the simulated realized gain and directivity are 32.8 and $33.3 \mathrm{dBi}$, making the corresponding antenna efficiency and aperture efficiency $86 \%$ and $95 \%$ for the $50.88 \mathrm{~mm} \times 50.88 \mathrm{~mm}$ aperture size. The cross polarization within the design frequency band is below $-67 \mathrm{~dB}$.

\section{Experimental Results}

The proposed antenna was fabricated by diffusion bonding of laminated thin copper plates, and a photograph of the fabricated prototype is shown in Fig. 14. The antenna is composed of ten etching patterns and the plates are $74 \mathrm{~mm} \times$ $74 \mathrm{~mm} \times 0.2 \mathrm{~mm}$. The total antenna dimension is $50.88 \mathrm{~mm}$ $\times 50.88 \mathrm{~mm} \times 5.8 \mathrm{~mm}\left(13.31 \lambda_{0} \times 13.31 \lambda_{0} \times 1.52 \lambda_{0}\right.$ at $78.5 \mathrm{GHz}$ ). Note that the through holes in the antenna prototype are used for screws in interconnecting the jig and the

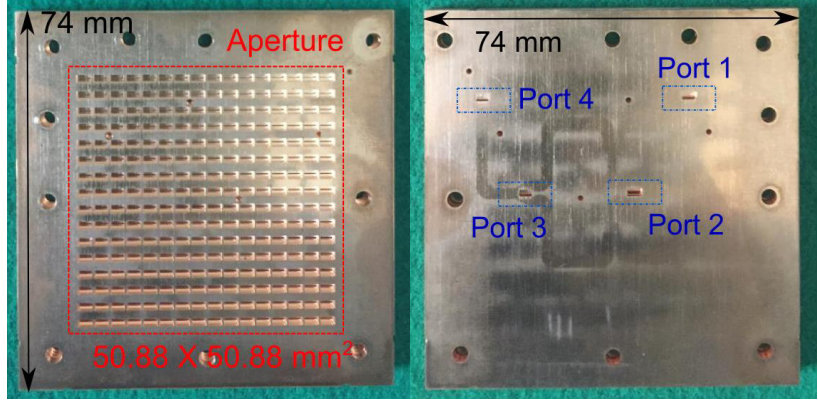

(a)

(b)

Fig. 14 Photograph of the fabricated prototype. (a) Front. (b) Back.

test system.

In the measurements, the unused ports are terminated with E-band matching loads. The far-field measurement is carried out by two test systems which operate in the V-band $(67-75 \mathrm{GHz})$ and the $\mathrm{W}$-band $(75-90 \mathrm{GHz})$, respectively.

\subsection{Reflection and Isolation}

Figure 15 shows the measured reflection and isolation characteristics of the antenna. The antenna exhibits a wide bandwidth for the impedance matching and also a high isolation level. The measured bandwidth of both input ports for VSWR $<2$ is $21.9 \%(70.0-87.2 \mathrm{GHz})$, matching well with its simulated counterpart. The measured reflection is slightly degraded in comparison with the simulated one. However, the wide bandwidth for VSWR $<2$ is confirmed in the measurement. The discrepancy between the simulated and measured reflection characteristics can be mainly attributed to the fabricated tolerance and the parasitic effect from the jig used for interconnecting the antenna and the test system. Within this bandwidth, the isolation between two of the input ports are better than $33.5 \mathrm{~dB}$. To facilitate the characterization, the bandwidth of both input ports for VSWR $<2$ is defined as the band of operation of the antenna here.

\subsection{Realized Gain, Directivity and Loss Evaluation of the Sum Beam}

The measured realized gain and directivity of the sum beam at the boresight are added in Fig. 12. At the design frequency of $78.5 \mathrm{GHz}$, the realized gain and directivity are 32.6 and $33.3 \mathrm{dBi}$, which correspond to antenna and aperture efficiencies of $83 \%$ and $95 \%$, respectively. The bandwidth for 1-dB gain down with respect to $78.5 \mathrm{GHz}$ is $19.2 \%$ (72.9$88.0 \mathrm{GHz}$ ). Across the operation band, an antenna efficiency $>73 \%$ and an aperture efficiency $>89 \%$ are fully supported. Across the operation band, the cross polarization is verified to be below $-44.2 \mathrm{~dB}$.

Within the operation band, the discrepancy between the measured realized gain and its simulated counterpart is mainly caused by the discrepancy between the measured and simulated reflection characteristics, as well as by the parasitic loss from the jig and the waveguide connectors used 


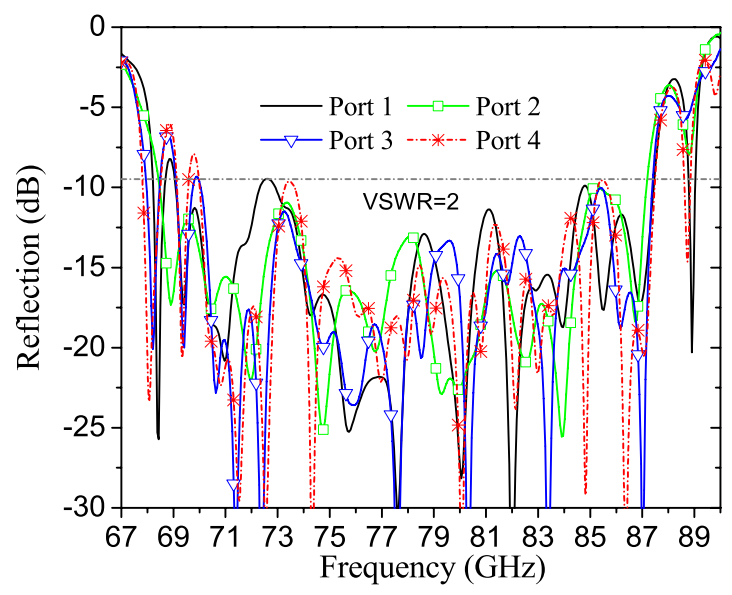

(a)

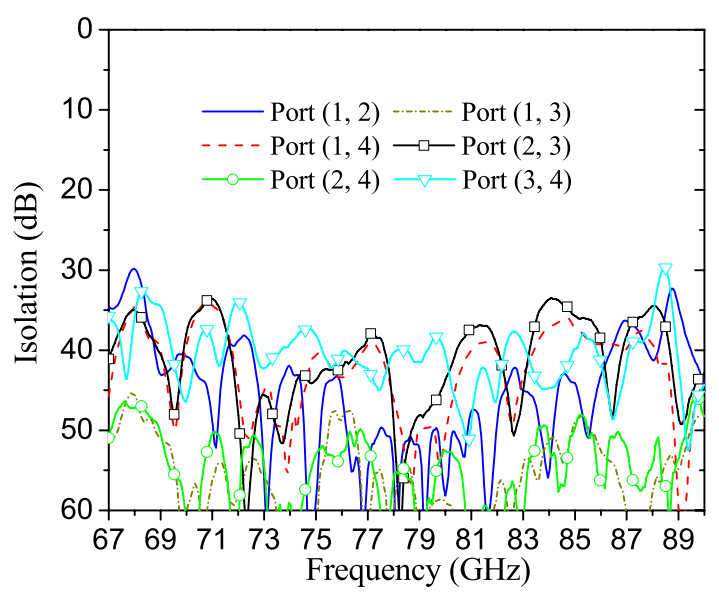

(b)

Fig. 15 Measured results of the antenna. (a) Reflection. (b) Isolation.

for interconnecting the antenna and the test system. This parasitic loss cannot be fully de-imbedded in measurement and it is roughly estimated to be less than $0.2 \mathrm{~dB}$ within the operation band.

Figure 16 shows the simulated and measured antenna losses which are estimated by the difference between the directivity and the realized gain while excluding the mismatching loss. Therefore, the simulated antenna loss is identical to the simulated conductor loss, while the measured antenna loss also includes the error in measurement and the leakage loss caused by the bonding imperfection. At $78.5 \mathrm{GHz}$, the simulated and measured losses are 0.43 and $0.39 \mathrm{~dB}$. Across the operation band, the measured loss is smaller than $0.85 \mathrm{~dB}$. The agreement between the simulated and measured results is evidence of the fabrication quality in terms of the surface roughness and the electric contact among the plates.

\subsection{Radiation Pattern}

Figure 17 shows the simulated and measured radiation patterns at $78.5 \mathrm{GHz}$. At $78.5 \mathrm{GHz}$, the measured first sidelobe level (SLL) of the sum beam in the E-, $\mathrm{H}-, 45^{\circ}$-, and $135^{\circ}$

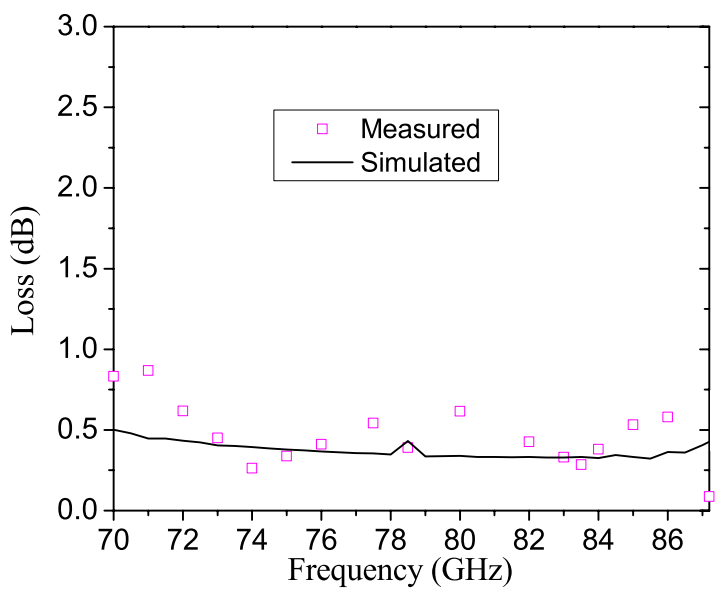

Fig. 16 Simulated and measured antenna losses.

Table 4 Amplitude difference of the peak gain between the sum and difference beams.

\begin{tabular}{ccccc}
\hline & E-plane & H-plane & $45^{\circ}$-plane & $135^{\circ}$-plane \\
\hline $\begin{array}{c}\text { Theoretical } \\
(\mathrm{dB})\end{array}$ & 3 & 3 & 6 & 6 \\
$\begin{array}{c}\text { Measured } \\
(\mathrm{dB})\end{array}$ & 2.85 & 3.18 & 6.10 & 6.03 \\
\hline
\end{tabular}

planes are $-13.3,-13.4,-27$, and $-26.5 \mathrm{~dB}$, with a $3-\mathrm{dB}$ beamwidth of $3.95^{\circ}, 3.85^{\circ}, 3.93^{\circ}$, and $3.92^{\circ}$, respectively. For the difference beams, the measured amplitude differences in the $\mathrm{E}-, \mathrm{H}-, 45^{\circ}$-, and $135^{\circ}$ - planes are $0.22,0.12$, 0.02 , and $0.12 \mathrm{~dB}$, with the high null depth level of -53.0 , $-58.0,-57.8$, and $-65.6 \mathrm{~dB}$, respectively. The amplitude differences of the peak gain between the sum and difference beams in each plane are detailed in Table 4. It shows that in the E- and H-planes, there is an approximately 3- $\mathrm{dB}$ difference in the measured peak gain between the respective sum and difference beams. Similarly, in the $45^{\circ}$ - and $135^{\circ}$-planes, there is an approximately 6-dB difference in the measured peak gain between the respective sum and difference beams. This suggests that high gain and high efficiency are also achieved for the difference beams.

Figure 18 shows the measured radiation patterns at different frequency points across the operation band. Here, the main-beam of the sum beam and the null of the difference beams are consistently pointing at the boresight.

Figure 19 shows details of the measured results in different planes across the operation band. The $3-\mathrm{dB}$ beamwidth of the sum beam in both planes is from $3.4^{\circ}$ to $4.0^{\circ}$. The SLL of the sum beam in the E-, $\mathrm{H}_{-}, 45^{\circ}-$, and $135^{\circ}$ planes are better than $-12.5,-12.7,-25.6$, and $-26.1 \mathrm{~dB}$, respectively, with no grating lobes observed. Besides, the amplitude difference in the E-, $\mathrm{H}-, 45^{\circ}$-, and $135^{\circ}$-planes are less than $0.28,0.26,0.37$, and $0.18 \mathrm{~dB}$, with the null depth lower than $-51.4,-52.0,-55.3$, and $-51.6 \mathrm{~dB}$, respectively.

Table 5 summaries the comparison with other related works at the design frequency. Note that in [13] the value of efficiency was given, however the type of efficiency such as radiation efficiency, aperture efficiency, and antenna effi- 


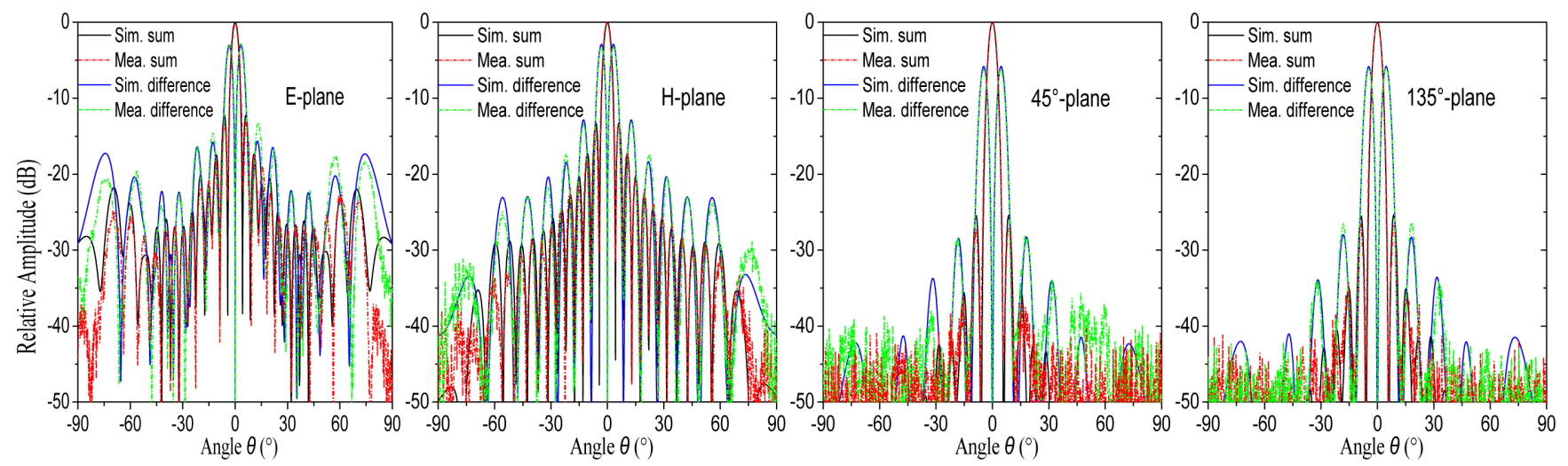

Fig. 17 Simulated and measured radiation patterns at the design frequency of $78.5 \mathrm{GHz}$ in different planes.
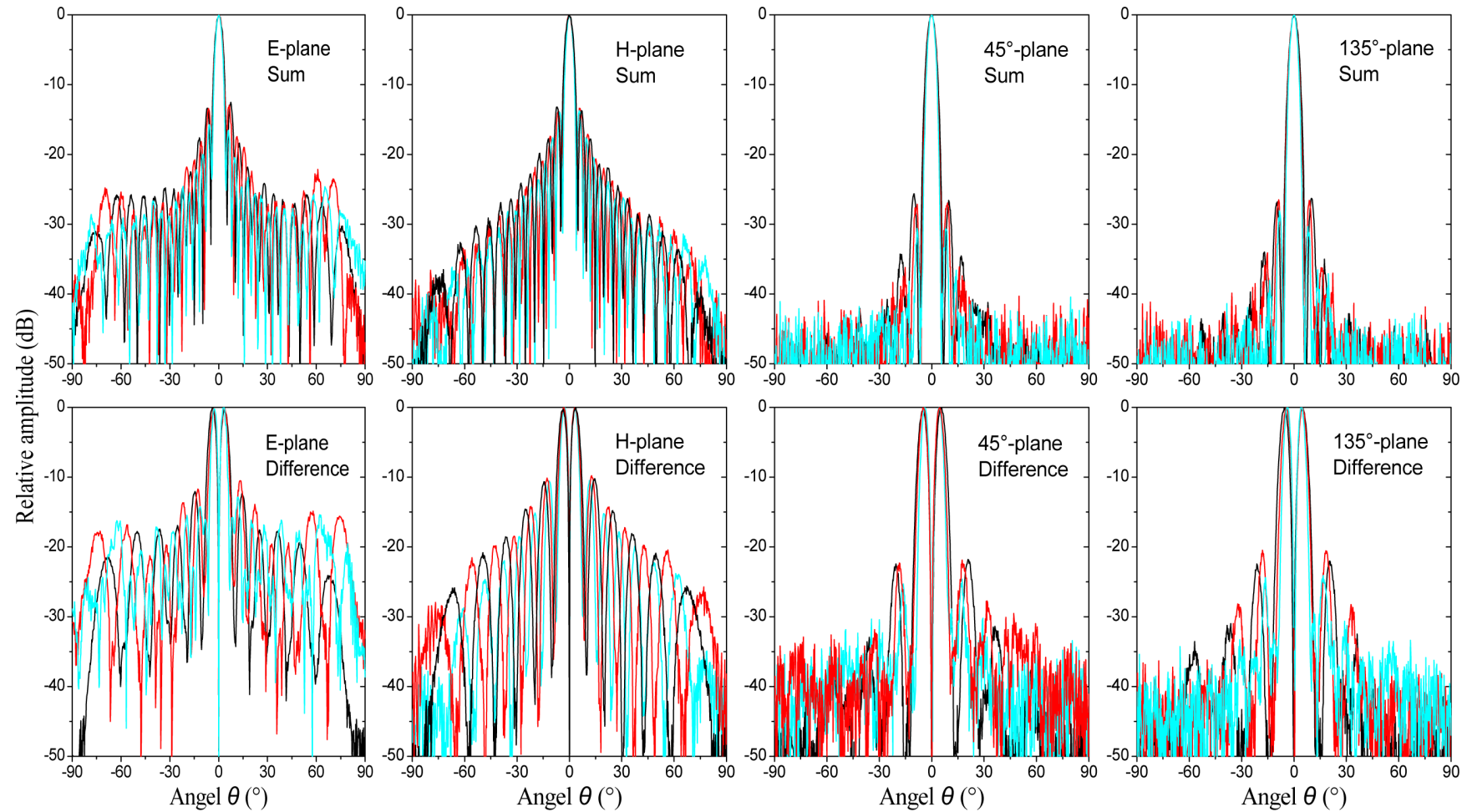

Fig. 18 Measured radiation patterns at 70 (black line), 78.5 (red line), and 87.2 (cyan line) GHz.

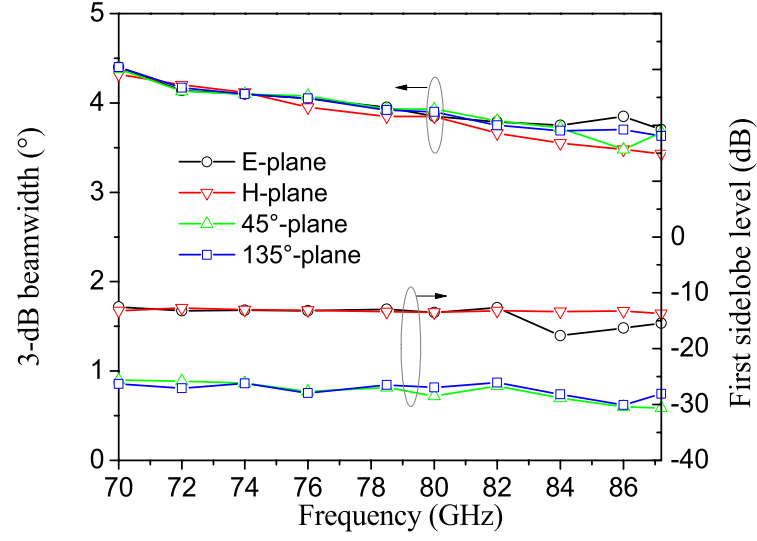

(a)

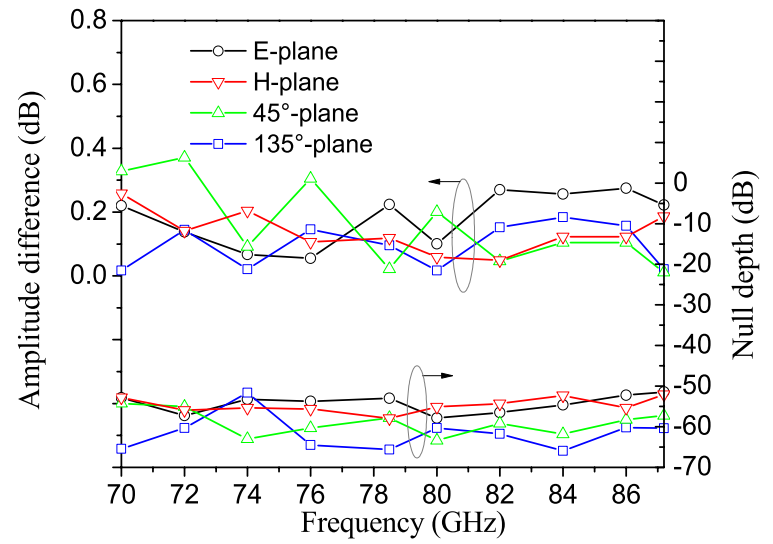

(b)

Fig. 19 Measured results. (a) 3-dB beamwidth and SLL of the sum beam. (b) Amplitude differences and null depth of the difference beam. 
Table 5 Comparison with other related work.

\begin{tabular}{|c|c|c|c|c|c|c|c|c|c|}
\hline Ref. & Architecture & $\begin{array}{l}\text { Radiating } \\
\text { element }\end{array}$ & $\begin{array}{c}\mathrm{f}_{0} \\
(\mathrm{GHz})\end{array}$ & $\begin{array}{c}\text { Operation } \\
\text { bandwidth } \\
(\%)\end{array}$ & $\begin{array}{l}\text { Sum-beam } \\
\text { realized gain } \\
\text { at } \mathrm{f}_{0} \\
(\mathrm{dBi})\end{array}$ & $\begin{array}{c}\text { Sum-beam } \\
\text { efficiency } \\
\text { at } f_{0} \\
(\%)\end{array}$ & \multicolumn{2}{|c|}{$\begin{array}{l}\text { Null depth } \\
\text { at } f_{0} \\
(\mathrm{~dB})\end{array}$} & Profile \\
\hline [7] & Multi-layer & $\begin{array}{l}\text { 144-slot } \\
\text { (RLSA) }\end{array}$ & 13.7 & $\approx 4.4$ & 18.2 & $\begin{array}{c}\approx 23.4 \\
\text { (ant. eff.) }\end{array}$ & \multicolumn{2}{|c|}{$\begin{array}{c}<-25 \\
\text { (circular polar.) }\end{array}$} & Planar \\
\hline [8] & Single-layer & $\begin{array}{l}16 \times 16 \text {-patch } \\
\text { (microstrip) }\end{array}$ & 14.25 & 5.6 & 24.5 & $\begin{array}{c}20 \\
\text { (ant. eff.) } \\
\end{array}$ & $\begin{array}{c}<-30 \\
\text { (E-plane) } \\
\end{array}$ & $\begin{array}{c}<-30 \\
\text { (H-plane) }\end{array}$ & Planar \\
\hline [9] & Single-layer & $\begin{array}{l}32 \times 32 \text {-slot } \\
(\mathrm{SIW})\end{array}$ & 94 & 3.2 & 25.21 & $\begin{array}{c}16.3 \\
\text { (rad. eff.) }\end{array}$ & $\begin{array}{c}-27.97 \\
\text { (E-plane) } \\
\end{array}$ & $\begin{array}{c}-27.60 \\
\text { (H-plane) }\end{array}$ & Planar \\
\hline$[10]$ & Multi-layer & $\begin{array}{l}26 \times 8 \text {-slot } \\
(\text { SIW })\end{array}$ & 24.15 & 4.5 & 22.65 & $\begin{array}{c}59.7 \\
\text { (rad. eff.) }\end{array}$ & \multicolumn{2}{|c|}{$\begin{array}{c}-20 \\
\text { (H-plane) } \\
\end{array}$} & Planar \\
\hline [11] & Multi-layer & $\begin{array}{c}284-\text {-slot } \\
\text { (waveguide) }\end{array}$ & 17 & 2.9 & $>29$ & - & \multicolumn{2}{|c|}{$\begin{array}{c}\approx-29 \\
\text { (azimuth plane) }\end{array}$} & Three-dimensional \\
\hline [12] & Multi-layer & $\begin{array}{c}820 \text {-slot } \\
\text { (waveguide) }\end{array}$ & - & 3.5 & - & $\begin{array}{c}65.3 \\
\text { (not given) }\end{array}$ & $\begin{array}{c}-35 \\
\text { (E-plane) }\end{array}$ & $\begin{array}{c}-35 \\
\text { (H-plane) }\end{array}$ & Three-dimensional \\
\hline [13] & Multi-layer & $\begin{array}{l}16 \times 16 \text {-slot } \\
\text { (waveguide) }\end{array}$ & 15 & 12.5 & 32.4 & $\begin{array}{c}95 \\
\text { (not given) } \\
\end{array}$ & $\begin{array}{c}-38 \\
\text { (E-plane) } \\
\end{array}$ & $\begin{array}{c}-36 \\
\text { (H-plane) } \\
\end{array}$ & Three-dimensional \\
\hline $\begin{array}{l}\text { This } \\
\text { work }\end{array}$ & Multi-layer & $\begin{array}{l}16 \times 16 \text {-slot } \\
\text { (waveguide) }\end{array}$ & 78.5 & 21.9 & 32.6 & $\begin{array}{c}83 \\
\text { (ant. eff.) }\end{array}$ & $\begin{array}{c}-53 \\
\text { (E-plane) }\end{array}$ & $\begin{array}{c}-58 \\
\text { (H-plane) }\end{array}$ & Quasi-planar \\
\hline
\end{tabular}

ciency as well as the antenna size for the efficiency estimation was not given. As shown, the proposed antenna here has a quasi-planar profile that ease of practical integration. The proposed antenna shows dramatic performance improvements in terms of operation bandwidth and null depth level. The proposed antenna also shows an encouragingly high antenna efficiency given such high operation frequency and complicated architecture.

\section{Conclusion}

In this paper, an E-band plate-laminated $16 \times 16$-slot fullcorporate-feed waveguide monopulse array antenna with compact size and low profile has been successfully demonstrated. The multi-layer architecture greatly facilitates the component design and interconnections, enabling a compact overall size and low losses. Stable radiation performance with excellent monopulse capabilities independent of the frequency is achieved by the well-designed sub-components associated with the full-corporate-feed architecture here.

The antenna demonstrates a wide operation bandwidth covering the full E-band with high isolation, high gain, high efficiency, and low cross polarization. Across the operation band, the antenna also demonstrates excellent monopulse capabilities with a narrow pencil beam and high null depth level. The antenna is promising and attractive for short-tomedium distance monopulse tracking radar applications with ultra-high range-resolution and high data-rate capabilities.

\section{References}

[1] S.M. Sherman and D.K. Barton, Mono-Pulse Principles and Techniques, 2nd ed., Artech House, Norwood, MA, USA, 2011.

[2] D.D. Howard, "High range-resolution monopulse tracking radar," IEEE Trans. Aerosp. Electron. Syst., vol.AES-11, no.5, pp.749-755. Sept. 1975.

[3] I. Gresham, A. Jenkins, R. Egri, C. Eswarappa, N. Kinayman, N. Jain, R. Anderson, F. Kolak, R. Wohlert, S.P. Bawell, J. Bennett, and J.-
P. Lanteri, "Ultra-wideband radar sensors for short-range vehicular applications," IEEE Trans. Microw. Theory Techn., vol.52, no.9, pp.2105-2122, Sept. 2004.

[4] N. Iwakiri, N. Hashimoto, and T. Kobayashi, "Performance analysis of ultra-wideband channel for short-range monopulse radar at KaBand," J. Electrical and Computer Engineering, vol.2012, Article ID 710752, 9 pages, 2012.

[5] J. Wells, Multigigabit Microwave and Millimeter-Wave Wireless Communications, Artech House, Boston, MA, USA, 2010.

[6] J. Wells, "New multi-gigabit wireless systems satisfy high-security rapid response applications," Military Embedded System, Spring, 2006.

[7] M. Sierra-Castaner, M. Sierra-Perez, M. Vera-Isasa, and J.L. Fernandez-Jambrina, "Low-cost monopulse radial line slot antenna," IEEE Trans. Antennas Propag., vol.51, no.2, pp.256-262, Feb. 2003.

[8] H. Wang, D.G. Fang, and X.G. Chen, "A compact single layer monopulse microstrip antenna array," IEEE Trans. Antennas Propag., vol.54, no.2, pp.503-509, Feb. 2006.

[9] Y.J. Cheng, W. Hong, and K. Wu, "94 GHz substrate integrated monopulse antenna array," IEEE Trans. Antennas Propag., vol.60, no.1, pp.121-129, 2012.

[10] K. Tekkouk, M. Ettorre, L.L. Coq, and R. Sauleau, "SIW pillbox antenna for monopulse radar applications," IEEE Trans. Antennas Propag., vol.63, no.9, pp.3918-3927, Sept. 2015.

[11] A.K. Singh, "A low cost, low side lobe and high efficiency nonorthogonally coupled slotted waveguide array antenna for monopulse radar tracking," IEEE Antennas and Propagation Society International Symposium, pp.732-735, July 2005.

[12] W.T. Zhang, F.Y. Cui, Q. Wang, X.Y. He, C.F. She, Y.Y. He, "Design of a waveguide slot array antenna for monopulse tracking application in millimeter wave," Proc. 12th European Radar Conference, pp.469472, Sept. 2015.

[13] G.-L. Huang, S.-G. Zhou, T.-H. Chio, C.-Y.-D. Sim and T.-S. Yeo, "Wideband dual-polarized and dual-monopulse compact array for SAR system integration," IEEE Geosci. Remote Sens. Lett., vol.13, no.8, pp.1203-1207, Aug. 2016.

[14] J. Hirokawa, D. Kim, K. Sakurai, M. Ando, T. Takada, and T. Nagatsuma, "Designs and measurements of plate-laminated waveguide slot array antennas for $120 \mathrm{GHz}$ band and $350 \mathrm{GHz}$ band," Asia Pacific Micro. Conf., pp.445-448, Dec. 2011.

[15] T. Tomura., J. Hirokawa, T. Hirano, and M. Ando, "A $45^{\circ}$ linearly polarized hollow-waveguide $16 \times 16$-slot array antenna covering 71-86 GHz band,” IEEE Trans. Antennas Propag.,vol.62, no.10, 
pp.5061-5067, Oct. 2014.

[16] M. Zhang, K. Toyosaki, J. Hirokawa, M. Ando, T. Taniguchi, and M. Noda, "A $60-\mathrm{GHz}$ band compact-range gigabit wireless access system using large array antennas," IEEE Trans. Antennas Propag., vol.63, no.8, pp.3432-3440, July 2015.

[17] T. Tomura, J. Hirokawa, T. Hirano, and M. Ando, "A wideband $16 \times 16$-element corporate-feed hollow-waveguide slot array antenna in the 60-GHz band," IEICE Trans. Commun., vol.E97-B, no.4, pp.798-806, April 2014.

[18] Y. Miura, J. Hirokawa, M. Ando, Y. Shibuya, and G. Yoshida, "Double-layer full-corporate-feed hollow-waveguide slot array antenna in the 60GHz-band," IEEE Trans. Antennas Propag., vol.59, no.8, pp.2844-2851, Aug. 2011.

[19] K.C. Hwang, "Design and optimization of a broadband waveguide magic-T using a stepped conducting cone," IEEE Microw. Wireless Compon. Lett., vol.19, no.9, pp.539-541, Sept. 2009.

[20] C.A. Leal-Sevillano, J.A. Ruiz-Cruz, J.R. Montejo-Garai, and J.M. Rebollar, "Compact broadband couplers based on the waveguide magic-T junction,” IEEE MTT-S Int. Microw. Symp. Dig., pp.151154, Oct. 2013

[21] W. Kahn, "E-plane forked hybrid-T junction," IRE Trans. Microw. Theory Techn., vol.MTT-3, no.6, pp.52-58, Dec. 1955.

[22] A.A. San Blas, F. Mira, V.E. Boria, B. Gimeno, M. Bressan, and P. Arcioni, "On the fast and rigorous analysis of compensated waveguide junctions using off-centered partial-height metallic posts," IEEE Trans. Microw. Theory Tech., vol.55, no.1, pp.168-175, Jan. 2007.

[23] X. Xu, J. Hirokawa, and M. Ando, "A waveguide slot array antenna with integrated T-shaped filters in the corporate-feed circuit," Proc. International Symposium on Antennas and Propagation (ISAP), Session S3.1.2, pp.45-46, Nov. 2015.

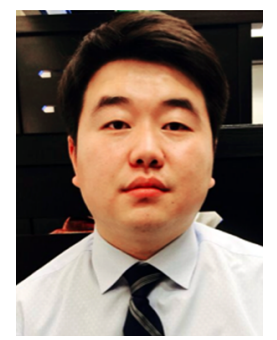

Xin Xu received the B.S., and M.S., degrees in Electrical Engineering from the University of Electronic Science and Technology of China (UESTC) and Nanjing University of Science and Technology (NJUST), China, in 2010 and 2014, respectively. Currently, he is working toward the D.E. degree at the Tokyo Institute of Technology (Tokyo Tech), Tokyo, Japan. His research interests include high-gain millimeterwave antennas.

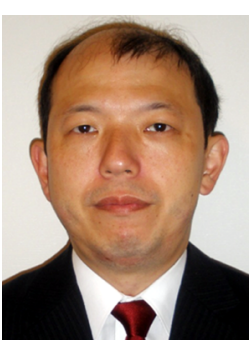

Jiro Hirokawa was born in Tokyo, Japan, on May 8, 1965. He received his B.S., M.S., and D.E. degrees in Electrical and Electronic Engineering from the Tokyo Institute of Technology (Tokyo Tech), Tokyo, Japan in 1988, 1990, and 1994, respectively. He is a Professor at Tokyo Tech from April 2015. From 1994 to 1995, he was with the antenna group of Chalmers University of Technology, Gothenburg, Sweden, as a Postdoctoral Fellow. His research area has been in slotted waveguide array antennas and millimeter-wave antennas. He received an IEEE AP-S Tokyo Chapter Young Engineer Award in 1991; a Young Engineer Award from IEICE in 1996; a Tokyo Tech Award for Challenging Research in 2003; a Young Scientists' Prize from the Minister of Education, Cultures, Sports, Science and Technology in Japan in 2005; a Best Paper Award in 2007; and a Best Letter Award in 2009 from IEICE Communication Society and Asia Pacific Microwave Conference best paper award in 2011, 2012 and 2013. He is a Fellow of IEEE and IEICE.

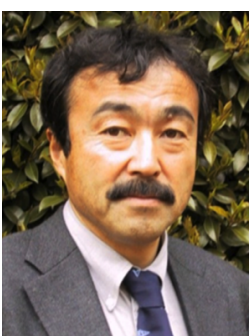

Makoto Ando was born in Hokkaido, Japan, on Feb. 16, 1952. He received his B.S., M.S., and D.E. degrees in Electrical Engineering from the Tokyo Institute of Technology, Tokyo, Japan in 1974, 1976, and 1979, respectively. From 1979 to 1983 , he worked at the Yokosuka Electrical Communication Laboratory, NTT, and was engaged in the development of antennas for satellite communication. He was a Research Associate at the Tokyo Institute of Technology from 1983 to 1985 and is currently a Professor. His main interests have been high-frequency diffraction theory, such as Physical Optics and Geometrical Theory of Diffraction. His research also covers the design of reflector antennas and waveguide planar arrays for DBS and VSAT. Latest interests include the design of high-gain millimeter-wave antennas. He received the Young Engineers Award in 1981, the Achievement Award in 1993, and the Paper Awards in 2009, all from IEICE Japan. He also received the 5th Telecom Systems Award in 1990, the 8th Inoue Prize for Science in 1992, the Meritorious Award of the Minister of Internal Affairs and Communications and the Chairman of the Board of ARIB in 2004, and the Award in Information Promotion Month 2006, the Minister of Internal Affairs and Communications. He served as the guest editor-in-chief of more than six special issues in IEICE, Radio Science, and IEEE AP. He was the general chair of the 2004 URSI EMT symposium in Pisa and the ISAP 2007 in Niigata. He served as the chair of the Technical committee of Electromagnetic theory (2004-2005) and Antennas and Propagation (2005-2007) in IEICE. He served as the member of the Administrative Committee of IEEE Antennas and Propagation Society from 2004 to 2006 and also as the member of the Scientific Council for Antenna Centre of Excellence (ACE) in EU's 6th framework program since 2004. He served as the Chair of Commission B of URSI from 2002 to 2005. He was the 2007 President of Electronics Society IEICE and the 2009 President of IEEE Antennas and Propagation Society. He is currently serving as the Program Officer for the Engineering Science Group in the Research Center for Science Systems, JSPS. He is a Fellow of IEEE and IEICE. 